\title{
Contraceptive use among Nigerian women with no fertility intention: interaction amid potential causative factors
}

\author{
${ }^{1,2^{*}}$ Stephen A. Adebowale (Ph.D) ${ }^{1},{ }^{2}$ Ikeola A. Adeoye (FMCPH) and \\ ${ }^{3}$ Martin E. Palamuleni (Ph.D) \\ ${ }^{1}$ Population Training and Research Unit, North-West University, Mafikeng, South Africa \\ ${ }^{2}$ Department of Epidemiology and Medical Statistics, Faculty of Public Health, College of Medicine, \\ University of Ibadan, Ibadan, Nigeria. \\ ${ }^{3}$ Population Training and Research Unit, North-West University, Mafikeng, South Africa
}

\begin{abstract}
High fertility (HF) remains a public health problem and the intention to reduce fertility is a global phenomenon. The health hazards and economic burden of HF on women are enormous. Contraception is widely known as a fertility reduction method. Achieving desirable MDGs and PoA of 1994 ICPD will be an illusion if research on the relationship between fertility intention and contraceptive use is neglected. The study which focused on 2,257 women of childbearing age who do not have any intention to bear more children utilized the Nigeria Demographic Health Survey, 2008 dataset. Data was analysed using Chi-square, binary and multinomial logistic regression $(=5.0 \%)$. The mean ages of the women and children ever born were $40.91 \pm 5.73$ years and $6.28 \pm 2.62$ respectively. The prevalence of Current Use of Any Contraceptive Method (CUACM) was $37.6 \%$, with $12.4 \%$ and $25.2 \%$ currently using natural and modern family planning methods respectively. About $7.0 \%$ of women in the poorest wealth quintile are CUACM compared to $61.8 \%$ of those in the richest wealth quintile. The current use of modern contraceptive prevalence rate was strikingly higher among Yorubas (4I.8\%) than Hausas (3.6\%). Multivariate analysis identified age, region, residence, education, ethnicity and family planning media exposure as significant predictors of CUACM. In addition, religion and decisions on how to spend family income were identified as predictors of current use of modern contraceptive methods $(p<0.05)$. The use of contraceptives is not adequately practised in Nigeria. The identified predictors of contraceptive use in this study should be considered while designing strategies to improve the contraceptive prevalence rate in Nigeria.
\end{abstract}

Keywords: Fertility intention, contraceptive use, Nigeria

\section{Introduction}

The 1994 International Conference on Population and Development (ICPD) articulated a vision of the relationships between population, development and individual well-being. At the ICPD, I79 countries adopted a forward-looking, 20-year Plan of Action (PoA) that built on the success of the population, maternal health and family planning programmes of the previous decades while addressing, with a new perspective, the needs of the early years of the twentyfirst century (UNFPA, 1994). Also, the Millennium Development Goals (MDGs) were conceived to encourage development by improving social and economic conditions in the world's poorest countries. It consists of a set of eight time-bound goals ranging from reducing poverty by half to improving maternal health (UN, 2000). Despite the global consensus on and commitment for the PoA and MDGs, periodic progress reports show that Nigeria is not "on track" for reaching the goals by 2015 (NDHS, 2008).

Population issues remain of decisive developmental concern in Nigeria, being the most populous country in Africa. Nigeria, with a population of over 170 million people, has a population growth rate of $2.6 \%$ per annum and total fertility rate of 5.6 (PRB, 20I2). The rapid population growth (RPG) is an impediment to meeting the themes of the PoA and MDGs. The health hazards and economic burden of RPG on family, particularly women who are primary care givers, are enormous. For instance, at the community level, rapid population growth adds to the number of people in need of healthcare, education, liveable wages, and other social services which, in turn, requires additional human,

I. *Corresponding author: Adehamilt2008@yahoo.com; Phone: +234335652I0h 
financial, material, and natural resources. At the household level, high fertility affects the health of women, their children, and families, thereby increasing the risk of maternal and childhood morbidity and mortality (USAID, 2009).

Contraceptive use plays a central role in terms of achieving the PoA of I 994 ICPD and is practically associated with all the eight themes of the MDGs. Development efforts to achieve the PoA and MDGs must recognize the benefits of slowing population growth. One way to slow population growth through the reduction of fertility and childhood mortality is to satisfy the current unmet need for family planning (Saha and Bairagi, 2007; UN, 2000; Goldberg et al., 1989). Therefore, achieving desirable MDGs and POA of ICPD will be an illusion if research on fertility intentions and contraceptive use is neglected in a country like Nigeria, which has maternal and childhood mortality rates of 550 / 100,000 women and 157/I,000 live births respectively and high rate of population growth (NDHS, 2008; Adebowale et al., 2010).

In response to the high population growth rate and its adverse effect on national development, the Federal Government of Nigeria approved the National Policy on Population for Development on February 4, 1988. Over the years, emerging issues such as HIV/AIDS, poverty, gender inequality, among others, gained wider recognition. This necessitated a review of the 1988 National Population Policy, giving way to the National Policy on Population for Sustainable Development (NPPSD) launched in February, 2005. The policy recognises that population factors, social and economic development, and environmental issues are irrevocably interrelated and are critical to the achievement of sustainable development in Nigeria (NPC and Macro International USA, 2009).

The overall goal of the NPPSD was based on the principle that achieving a higher quality of life for people today should not jeopardise the ability of future generations to meet their own needs (NPC, 2004). To guide the policy, programme planning, and its implementation, the following targets were set: reduce the national population growth rate to 2 percent or lower by 2015 , reduce the total fertility rate by at least 0.6 children every five years by encouraging child spacing through the use of family planning, increase the contraceptive prevalence rate for modern methods by at least two percentage points per year through the use of family planning, reduce the infant mortality rate to 35 per 1,000 live births by 2015 , reduce the child mortality rate to 45 per I,000 live births by 2010 , reduce the maternal mortality ratio to 125 per 100,000 live births by 2010 and to 75 by 2015 , achieve sustainable universal basic education as soon as possible before 2015, eliminate the gap between males and females in school enrolment at all levels and in vocational and technical education by 2015 , eliminate illiteracy by 2020 , achieve at least a 25 percent reduction in HIV/ AIDS adult prevalence every five years.

Research on contraceptive use in Nigeria, particularly on those that are related to fertility intention, is indispensable to monitor the progress made so far in terms of upholding the tenets of NPPSD. Fertility intentions have been found to influence future fertility behavior (Umoh, 20I2). Women without fertility intention refers to those who have possibly achieved their desired family size and are no longer interested in having additional children. However, these categories of women may still be at risk of unwanted pregnancy and as such still require contraception. Our study seeks to explore the determinants and levels of contraceptive use among women of reproductive age without fertility intentions, using a nationally representative 2008 NDHS data set. The level of current use is a measure of actual contraceptive practice at the time of the survey. It is also the most widely used and valuable measure of the success of family planning programmes. Furthermore, it can be used to estimate the reduction in fertility attributable to contraception.

In Nigeria, different studies have been conducted on contraceptive use (Adebowale et al., 20II; Adebowale et al., 2012; NDHS, 2008; NDHS, 2003; Odimegwu et al., 1997), but information is still insufficient since the contraceptive issue is of national and global importance. Our study therefore assesses the level of contraceptive use among Nigerian women who wish to halt fertility permanently. It also identifies some demographic and socio-economic factors that influence the use of any and modern contraceptive methods in Nigeria. This is with a view to assisting family planning programmers in their strategies towards fertility reduction in Nigeria. 


\section{Importance and determinants of contraceptive use}

Population-related issues are integral parts of cultural, economic and social development, the principal aim of which is to improve the quality of life of all people (UNFPA, 1994). In the African context, the provision of contraceptives is an exigent task and ignorance of sexual issues is often seen as a sign of purity; women find it dishonourable to talk about sex and its diverse consequences. These general attitudes have prevented some women from looking for accurate reproductive and sexual information from reliable sources, particularly those that are related to contraceptives. Contraception has proved to be very important in the control of fertility. The inverse relationship between contraceptive use prevalence and children ever born is well established in the literature (Adebowale et al., 20II; Satyavada and Adamchak, 2000; Odimegwu et al., 1997; Shah and Kazi, 1977). It has been possible for several countries of the world to keep their population sizes under control by promoting the use of contraceptives among women of reproductive age who are sexually active. The prevalence of contraceptive use in Nigeria is about 13\%, in spite of a high level of awareness of the available contraceptive methods among her citizenry (NDHS, 2008).

Contraceptive use assists couples in achieving their desired children either by proper spacing or limiting pregnancies, which invariably protects the health of the mother, and ensures optimal growth and development of the child (Arab et al., 20II). It also protects sexually active women from the risk of unwanted pregnancies, unsafe abortion, reproductive tract infections, and sexually transmitted infections including HIV/AIDs (Moronkola et al., 2006). Generally, the failure to use contraceptives contributes to the burden of ill-health among women of reproductive age resulting from a large number of unplanned pregnancies as well as shortened inter-pregnancy intervals. For instance, women of reproductive age who do not want to bear any children who are not using contraceptives often result in unwanted pregnancies, unsafe abortions, with the attendant complications including partial or total disabilities in some vital organs, eventually leading to possible untimely death. Bankole and his colleagues showed that $60 \%$ of women with unplanned pregnancy in Nigeria did not use any form of contraception (Bankole et al., 2006).

Previous studies have explored the determinants of contraceptive use among women of reproductive age; in most cases they have included both demographic and socio-economic factors. For instance, Odimegwu et al. in their study on contraceptive use in Nigeria reported age, level of education, religion, family planning approval, media exposure and place of residence as important correlates of contraceptive use (Odimegwu et al., 1997). Also, Oyedokun in his study specifically identified the female's education as a strong predictor of contraceptive use (Oyedokun, 2007). Lack of adequate information, ignorance, spousal communication and consent and fear of side-effects were found to be determinant of contraceptive use in OmoAghoja's study (Omo-Aghoja, 2009). In some countries, child sex preference is a major determinant of contraceptive use; at the same time the loss of a child usually has a negative impact on contraceptive use (Radheshyam Bairagi, 200I). Couples who have experienced the loss of a child are more likely to desire more children and therefore will not likely use contraceptives, compared to those who don't have a similar experience (Mensch, 1985).

\section{Data and methods}

\section{Brief description of Nigeria}

Nigeria came into existence as a nation-state in 1914 through the amalgamation of the Northern and Southern protectorates. Nigeria became fully independent in October 1960 as a federation of three regions (Northern, Western, and Eastern). There are about 374 identifiable ethnic groups, with the Igbo, Hausa, and Yoruba as major groups. Presently, Nigeria is made up of 36 states and a Federal Capital Territory (FCT), grouped into six geopolitical zones: North Central, North East, North West, South East, South South, and South West. The country's economic strength is derived largely from its oil and gas reserves, which make up 99 percent of export revenues, 78 percent of government revenues, and 38.8 percent of the GDP; the real GDP growth rate was estimated at 6.0 percent (CBN, 2002). Nigeria is the largest 
country in Africa with a population figure of above 170 million and among the top ten most populous countries in the World (PRB, 20I2).

\section{Data source}

Nigeria Demographic Health Survey (NDHS), 2008 dataset was used with a focus on women of childbearing age. The data were originally collected by National Population Commission, Nigeria and Macro International in United States of America. Data were extracted from Measure DHS database (http://www.measuredhs.com/). The data is secondary; therefore the data collection procedures are contained in the NDHS 2008 report available at the website of the data originator (http://www.measuredhs.com/).
Originally, a national representative sample of 33,385 women of childbearing age was selected and cross examined using a well structured pretested questionnaire. Nevertheless, our study included only women who do not want to bear any children and ever had sexual intercourse. Other criteria for women's selection for the study are that any selected woman must not be declared infecund, not pregnant, not breast feeding and sexually active (having sex in the 4 weeks preceding the survey). Excluding women who did not meet the above criteria reduces the sample to 2,257 women with a view to removing possible effects of bias that their inclusion might cause on the results.

$$
\text { WIS }_{15-49}=\text { TWS }_{15-49}-W H W B_{15-49}-W_{N H S I_{15-49}}-W D I_{15-49}-W B F_{15-49}-W R P_{15-49}-W N S I_{15-19}
$$

Where; WIS $_{15-49}=$ Women included in the study aged 15-49;TWS $15-49=$ Total women sampled aged 15-49; WHWB WH-49 $_{15}=$ Women who wanted to bear more children now or in future aged 15-49; WNHSI $_{15-49}=$ Women who never had sexual intercourse aged I5-49; $\mathrm{WDI}_{15-49}=$ Women who must have been declared infecund aged 15-49; $\mathrm{WBF}_{15-49}=$ Women who are breastfeeding aged 15-49; $\mathrm{WRP}_{15-49}=$ Women who are recently pregnant aged I5-49

\section{Measurement of key variables}

Current contraceptive use was measured only among women who had had sex in the 4 weeks prior to the survey and refers to the method used in the most recent month she had sex. Among women who reported using multiple methods in the survey month, priority was given to the most effective method. The category of "other" methods mainly consists of withdrawal but also includes less common methods, such as suppositories, sponges and foams. Natural family planning includes periodic abstinence, temperature rhythm and cervical mucus tests.

Contraceptive methods are classified as modern or traditional. Modern methods include female sterilisation, male sterilisation, the pill, intra-uterine device (IUD), injectables, implants, male condom, female condom, diaphragm, foam/jelly, lactational amenorrhoea method (LAM), and emergency contraception. Methods such as rhythm (periodic abstinence) and withdrawal are grouped as traditional methods. Pro- vision was also made in the questionnaire to record any other methods mentioned by the respondent, including folk methods (National Population Commission Nigeria and ICF Macro 2009).

\section{Data analysis}

The data was weighted by setting the 'weighting variable on' to remove the effect of cluster design which was used during the data collection exercise to ensure a suitably representative sample for subgroup analysis. Data was analysed using Descriptive statistics, Chi-square, binary and multinomial logistic regression models (=5.0\%). The dependent variables were "current use of contraceptive" modern or any contraceptive method which was coded as 0 if the respondent is not currently using a contraceptive method and $\mathrm{I}$ if otherwise. At bivariate, Chi-square was used to examine the association between the dependent variable and independent variables such as age, education, religion, residence, wealth quintile, etc. Independent variables found to be significant at bivariate $(5.0 \%)$ were entered into binary and multinomial logistic regression models in order to identify those that are causal of current use of contraceptive.

Binary logistic regression was used when current use of 'any contraceptive method' (both natural and modern) was used as dependent variable. The logistic regression is of the form: 


$$
\log \left\{\frac{\varphi}{1-\varphi}\right\}=\alpha_{0}+\alpha_{1} x_{1}+\alpha_{2} x_{2}+\alpha_{3} x_{3}+\ldots+\alpha_{n} x_{n}
$$

Where; $\varphi=1 \varphi=1$ represents the proportion of women who are currently using any contraceptive method and $\varphi=0 \varphi=0$, if otherwise.

The independent variables are

$$
\begin{aligned}
& \mathrm{x}_{1}, \mathrm{x}_{2}, \mathrm{x}_{3}, \ldots, \mathrm{x}_{\mathrm{n}} \mathrm{x}_{1}, \mathrm{x}_{2}, \mathrm{x}_{3}, \ldots, \mathrm{x}_{\mathrm{n}} \text { and } \\
& \propto_{0}, \propto_{1}, \propto_{2}, \propto_{3}, \ldots, \propto_{\mathrm{n}} \propto_{0}, \propto_{1}, \propto_{2}, \propto_{3}, \ldots, \propto_{\mathrm{n}} \text { are }
\end{aligned}
$$

regression parameters to be estimated. The odd ratio $\left(e^{\alpha}\right)\left(e^{\alpha}\right)$ and $95 \%$ confidence interval of $\mathrm{e}^{\alpha} \mathrm{e}^{\alpha}$ were thereafter determined.

Also, multinomial logistic regression was used to predict categorical placement in current use of modern contraceptive based on multiple independent variables such as age, number of surviving children, education, etc. This is because the dependent variable in this case is more than two categories (non users, using natural method, and using modern method). The model uses maximum likelihood estimation to evaluate the prob-

$\mathrm{p}\left(\mathrm{Y}_{\mathrm{i}}=\mathrm{m}\right)=\frac{\exp \left(\mathrm{Z}_{\mathrm{mi}}\right)}{1+\sum_{\mathrm{h}=2}^{3} \exp \left(\mathrm{Z}_{\mathrm{hi}}\right)}$

For the reference category;

$$
\mathrm{p}\left(\mathrm{Y}_{\mathrm{i}}=1\right)=\frac{1}{1+\sum_{\mathrm{h}=2}^{3} \exp \left(\mathrm{Z}_{\mathrm{hi}}\right)}
$$

In other words, each of the computed $3-I=2$ log odds was exponentiated.

We based our analysis using multinomial logistic regression on the assumptions that: data are case specific which means that each independent variable has a single value for each case, non-perfect separation because, if the groups of the outcome variable are perfectly separated by the predictor(s), then unrealistic coefficients will be estimated and effect sizes will be greatly exaggerated.

\section{Results}

The summary statistics for children ever born to the respondents are as shown in Figurel. The data show that the mean children ever born was ability of categorical membership of each type of contraceptive method used.

In view of the fact that the dependent variable has 3 categories, this requires the calculation of 3 $\mathrm{I}=2$ equations, one for each category relative to the reference category (not using any contraceptive method), to describe the relationship between modern contraceptive use and the independent variables. We chose the first category (non-users) as the reference, then, for $\mathrm{m}=2,3$

$\ln \left\{\frac{\mathrm{p}\left(\mathrm{Y}_{\mathrm{i}}=\mathrm{m}\right)}{\mathrm{p}\left(\mathrm{Y}_{\mathrm{i}}=1\right)}\right\}=\alpha_{\mathrm{m}}+\sum_{\mathrm{k}=1}^{\mathrm{K}} \beta_{\mathrm{mk}} \mathrm{X}_{\mathrm{ik}}=\mathrm{Z}_{\mathrm{mi}}$

Hence, for each case, there will be 2 predicted log odds, one for each category relative to the reference category. When there are more than 2 groups, computing probability is a little more problematical than it was in logistic regression. For $m=2,3$

highest among women who were not using contraceptives $(6.85 \pm 2.82)$ during sexual intercourse within 4 weeks prior to the survey as compared with those who used either natural $(5.45 \pm \mathrm{I} .86)$ or modern $(5.30 \pm \mathrm{I} .90)$ or any $(5.35 \pm 1.89)$ of the methods.

The prevalence of current use of any contraceptive method was $37.6 \%$ with $12.4 \%$ and $25.2 \%$ currently using natural and modern family planning methods respectively. Across the subgroup of women, among those who used any contraceptive method, the majority used a modern method. The mean age of the women was $40.91 \pm 5.73$ years and a significant difference existed between the mean age of women who never and those who currently used any 
contraceptive method during sexual intercourse in the 4 weeks prior to the survey. Among all age categories, the highest proportion of women in age group 25-34 years used any contraceptive method, of which $42.4 \%$ used modern and $14.4 \%$ used natural methods. It is interesting to know that all (100.0\%) female youths who currently used any contraceptive method used a modern method. A higher percentage of women who had at least 3 living children used any contraceptive method as against those who had fewer than 3 children.

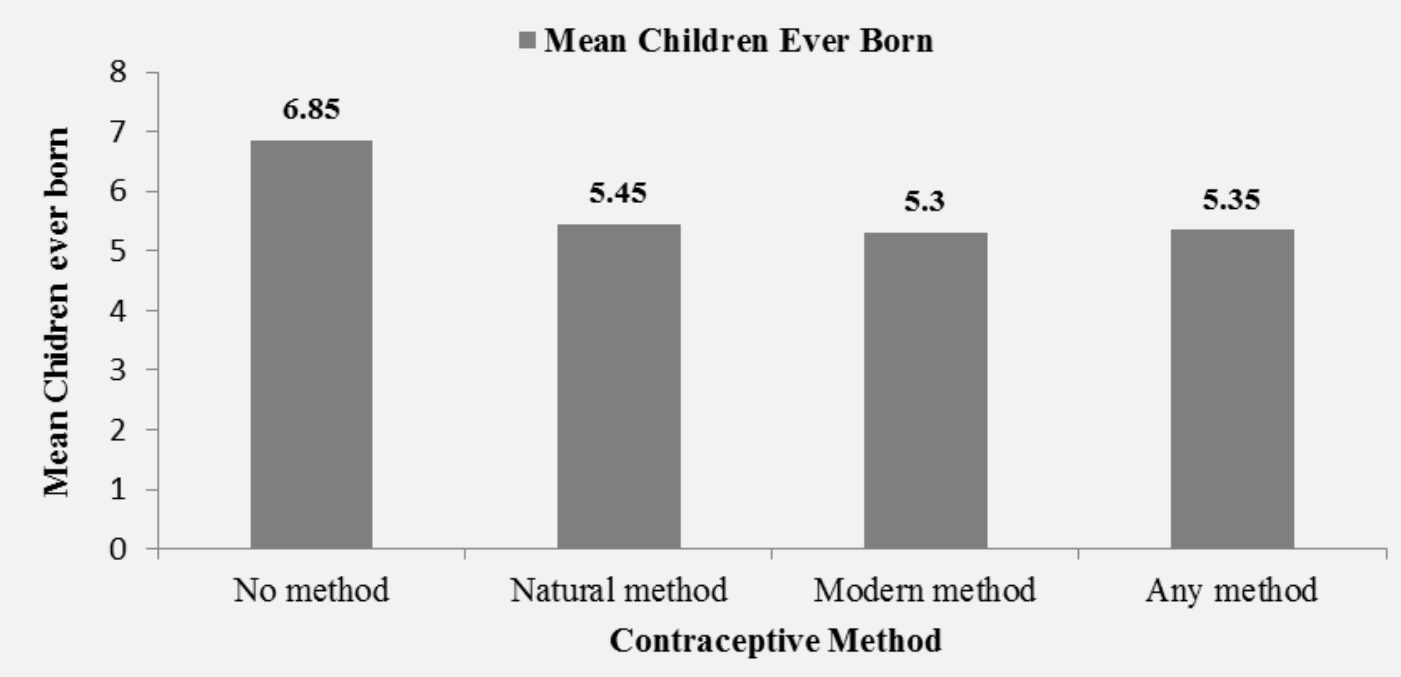

The data further revealed that current contraceptive use was higher among Christians (49.0\%) than Muslims (20.4\%). Wide differentials exist in current contraceptive use by region and a higher proportion of women who currently used contraception were found in all the regions in the southern part of Nigeria than any of the regions in the North. Highest prevalence of current use of contraceptive was found among women residing in the South West
(61.5\%) and least in North East (6.5\%). In terms of education, the proportion of women who used any contraceptive method increases with increasing levels of education. For example, only II.8\% of women with no formal education currently used any contraceptive method as against $61.9 \%$ of their counterparts in higher levels of education. (See Table I in Appendix B for further details of patterns of contraceptive use).

Table I Currently using contraceptive by method type according to demographic characteristics

\begin{tabular}{|c|c|c|c|c|c|c|c|}
\hline $\begin{array}{l}\text { Background } \\
\text { Characteristics }\end{array}$ & $\begin{array}{l}\text { Any } \\
\text { method }\end{array}$ & 2 -value & $\mathrm{p}$-value & $\begin{array}{l}\text { Natural } \\
\text { method }\end{array}$ & $\begin{array}{l}\text { Modern } \\
\text { method }\end{array}$ & 2 -value & $\mathrm{p}$-value \\
\hline & $\%(n)$ & & & $\%(n)$ & $\%(n)$ & & \\
\hline Total & $37.6(848)$ & & & $12.4(279)$ & $25.2(569)$ & & \\
\hline Age & & 42.127 & $p<0.0001$ & & & 57.344 & $p<0.0001$ \\
\hline $15-24$ & $35.0(7)$ & & & $0.0(0)$ & $35.0(7)$ & & \\
\hline $25-34$ & $56.8(150)$ & & & $14.4(38)$ & $42.4(I \mid 2)$ & & \\
\hline $35-49$ & $35.0(691)$ & & & $\mid 2.2(24 \mid)$ & $22.8(450)$ & & \\
\hline Mean \pm SD & $38.95 \pm 5.2$ & & $p<0.0001$ & $39.28 \pm 4.6$ & $38.79 \pm 5.5$ & & $p<0.0001$ \\
\hline NSC & & 36.604 & $p<0.000 I$ & & & 38.399 & $\mathrm{p}<0.000 \mathrm{I}$ \\
\hline 0 & $14.3(2)$ & & & $0.0(0)$ & $\mid 4.3(2)$ & & \\
\hline $\mathrm{I}-2$ & $24.8(37)$ & & & $6.7(10)$ & I8.I(27) & & \\
\hline $3-4$ & $45.5(328)$ & & & $15.8(1 \mid 4)$ & $29.8(215)$ & & \\
\hline $5+$ & $35.0(48 I)$ & & & II.3(I55) & $23.7(326)$ & & \\
\hline Mean \pm SD & $4.84 \pm 2.2$ & & $p<0.0001$ & $4.85 \pm 1.5$ & $4.83 \pm 1.6$ & & $p<0.0001$ \\
\hline
\end{tabular}




\begin{tabular}{|c|c|c|c|c|c|c|c|}
\hline Religion & & 189.30 & $\mathrm{p}<0.000 \mathrm{I}$ & & & 191.50 & $\mathrm{p}<0.000 \mathrm{I}$ \\
\hline Christianity & $49.0(659)$ & & & $15.6(210)$ & $33.4(449)$ & & \\
\hline Islam & $20.4(175)$ & & & $7.5(64)$ & $13.0(111)$ & & \\
\hline Traditional & $14.7(5)$ & & & $8.8(3)$ & $5.9(2)$ & & \\
\hline Others & $42.9(9)$ & & & $9.5(2)$ & $33.3(7)$ & & \\
\hline Region & & 419.20 & $\mathrm{p}<0.000 \mathrm{I}$ & & & 444.50 & $\mathrm{p}<0.000 \mathrm{I}$ \\
\hline North Central & $36.1(108)$ & & & $7.4(22)$ & $28.8(86)$ & & \\
\hline North East & $6.5(16)$ & & & $1.2(3)$ & $5.3(13)$ & & \\
\hline North West & $9.8(42)$ & & & $1.4(6)$ & $8.4(36)$ & & \\
\hline South East & $48.1(113)$ & & & $22.6(53)$ & $25.5(60)$ & & \\
\hline South South & $41.2(156)$ & & & $16.4(62)$ & $24.8(94)$ & & \\
\hline South West & $61.5(4 \mid 3)$ & & & $19.7(132)$ & $41.8(280)$ & & \\
\hline Residence & & 164.50 & $p<0.0001$ & & & 164.60 & $\mathrm{p}<0.000 \mathrm{I}$ \\
\hline Urban & $52.8(507)$ & & & $17.3(166)$ & $35.5(34 I)$ & & \\
\hline Rural & $26.3(34 I)$ & & & $8.7(113)$ & $17.6(228)$ & & \\
\hline Education & & 398.40 & $p<0.0001$ & & & 404.30 & $p<0.0001$ \\
\hline No education & $11.8(95)$ & & & $4.1(33)$ & $7.7(62)$ & & \\
\hline Primary & $42.2(237)$ & & & $12.3(69)$ & $29.9(168)$ & & \\
\hline Secondary & $57.0(364)$ & & & $20.8(133)$ & $36.2(23 I)$ & & \\
\hline Higher & $61.7(153)$ & & & I7.8(44) & $43.7(108)$ & & \\
\hline Marital status & & 4.309 & 0.116 & & & 6.687 & 0.153 \\
\hline Never & $35.7(5)$ & & & $0.0(0)$ & $35.7(5)$ & & \\
\hline Currently & $37.2(808)$ & & & $12.3(267)$ & $24.9(54 I)$ & & \\
\hline Formerly & $49.3(35)$ & & & $16.9(12)$ & $32.4(23)$ & & \\
\hline \multicolumn{2}{|c|}{ Husband's education } & 352.40 & $p<0.0001$ & & & 329.10 & $p<0.0001$ \\
\hline No education & $10.6(72)$ & & & $3.2(22)$ & $7.3(50)$ & & \\
\hline Primary & $43.7(258)$ & & & $15.8(93)$ & $28.0(165)$ & & \\
\hline Secondary & $51.5(302)$ & & & $17.7(104)$ & $33.8(198)$ & & \\
\hline Higher & $56.5(203)$ & & & $16.4(59)$ & $40.1(144)$ & & \\
\hline Don't know & $33.3(3)$ & & & $10.0(1)$ & $30.0(3)$ & & \\
\hline
\end{tabular}

NSC: Number of Surviving Children

The percentage of contraceptive use also increases as the level of wealth quintile increases. It increases considerably from $7.0 \%$ among women in the poorest wealth quintile to $61.8 \%$ among those in the richest wealth quintile. Women who were working used contraceptives more $(42.0 \%)$ than their counterparts who were not working $(18.7 \%)$. It is striking that a wide gap exists in modern contraceptive use between the three major ethnic groups in Nigeria. For instance, the current use of any contraceptive method among the Yorubas, Igbo and Hausa was $60.6 \%, 54.3 \%$ and $5.2 \%$ respectively. A similar pattern was observed in the current use of modern contraceptives among the ethnic groups, with the highest prevalence observed among Yorubas (4I.8\%) and least among the Hausas (3.6\%).
Higher prevalence of contraceptive use was found among women who decide jointly with their partnerson how to spend money (54.6\%) and also among those who were the sole decision maker on own health care (50.2\%). Prevalence of use of modern contraceptives was highest among women whose husbands do not contribute financially to family care (33.3\%). Current use of any and modern contraceptive methods were most common among women with a high exposure to media information (radio, television and newspaper). Women who had been exposed to family planning programmes in the media in the last 2 months before the survey currently use any (52.6\%) and modern (35.4\%) contraceptive methods more than those who did not have such expo- 
sure (Table 2 in Appendix C).

Table 2 Currently using contraceptive by method type according to socioeconomic characteristics

\begin{tabular}{|c|c|c|c|c|c|c|c|}
\hline $\begin{array}{l}\text { Background } \\
\text { characteristics }\end{array}$ & $\begin{array}{l}\text { Any } \\
\text { method }\end{array}$ & $X^{2}$-value & $\mathrm{p}$-value & $\begin{array}{l}\text { Natural } \\
\text { method }\end{array}$ & $\begin{array}{l}\text { Modern } \\
\text { method }\end{array}$ & $X^{2}$-value & $\mathrm{p}$-value \\
\hline & $\%(n)$ & & & $\%(n)$ & $\%(n)$ & & \\
\hline Total & $37.6(847)$ & & & $12.4(279)$ & $25.2(570)$ & & \\
\hline Wealth quintile & & 387.2 & $p<0.0001$ & & & 386.10 & $p<0.0001$ \\
\hline Poorest & $7.0(23)$ & & & $1.8(6)$ & $5.5(18)$ & & \\
\hline Poorer & $20.3(74)$ & & & $7 . I(26)$ & I3.4(49) & & \\
\hline Middle & $26.3(101)$ & & & $8.9(34)$ & I7.4(67) & & \\
\hline Richer & $44.7(205)$ & & & I6. I(74) & $28.5(131)$ & & \\
\hline Richest & $61.8(444)$ & & & 19.3(139) & $42.4(305)$ & & \\
\hline Ethnicity & & 365.2 & $\mathrm{p}<0.000 \mathrm{I}$ & & & 154.23 & $p<0.0001$ \\
\hline Hausa & $5.2(19)$ & & & $1.9(7)$ & $3.6(13)$ & & \\
\hline lgbo & $54.3(191)$ & & & $23.0(81)$ & $31.2(110)$ & & \\
\hline Yoruba & $60.6(359)$ & & & $18.9(112)$ & $41.8(248)$ & & \\
\hline Others & 29.4(279) & & & $8.4(80)$ & $20.9(199)$ & & \\
\hline Work status & & 77.023 & $\mathrm{p}<0.000 \mathrm{I}$ & & & 77.601 & $\mathrm{p}<0.000 \mathrm{I}$ \\
\hline Not working & $18.7(76)$ & & & $5.2(21)$ & $13.5(55)$ & & \\
\hline Working & $42.0(772)$ & & & $14.0(258)$ & $27.9(5 \mid 4)$ & & \\
\hline \multicolumn{2}{|c|}{ Decision on how to SM } & 29.245 & $p<0.0001$ & & & 38.412 & $\mathrm{p}<0.0001$ \\
\hline Respondent & $38.8(372)$ & & & $14.4(138)$ & $24.4(234)$ & & \\
\hline Respt. \& H/P & $54.6(215)$ & & & $14.2(56)$ & $40.4(159)$ & & \\
\hline $\mathrm{H} / \mathrm{P}$ alone & $45.2(75)$ & & & $16.9(28)$ & $28.3(47)$ & & \\
\hline \multicolumn{2}{|c|}{ Final say on own HC } & 123.50 & $\mathrm{p}<0.000 \mathrm{I}$ & & & 143.00 & $\mathrm{p}<0.0001$ \\
\hline Respt. alone & $50.2(148)$ & & & $2 I . I(62)$ & $28.9(85)$ & & \\
\hline Respt. \& H/P & $45.5(445)$ & & & $13.6(133)$ & $31.9(3 \mid 2)$ & & \\
\hline $\mathrm{H} / \mathrm{P}$ alone & $23.8(211)$ & & & $7.7(68)$ & $16.2(144)$ & & \\
\hline \multicolumn{2}{|c|}{ Earns more than partner } & 1.856 & 0.762 & & & 19.321 & 0.013 \\
\hline More than him & $48.2(4 I)$ & & & $15.3(13)$ & $32.9(28)$ & & \\
\hline Less than him & $42.7(529)$ & & & $13.7(169)$ & $29.0(359)$ & & \\
\hline About the same & $46.0(52)$ & & & $13.3(15)$ & $32.7(37)$ & & \\
\hline PDBM & $50.0(6)$ & & & $16.7(2)$ & $33.3(4)$ & & \\
\hline Don't know & $46.5(33)$ & & & $30.6(22)$ & $16.7(12)$ & & \\
\hline Media exposure & & 286.90 & $p<0.0001$ & & & 295.1 & $\mathrm{p}<0.0001$ \\
\hline No exposure & I3.I(59) & & & $4.0(18)$ & $9 . I(4 I)$ & & \\
\hline Low exposure & $28.0(2 \mid 2)$ & & & $11.6(88)$ & $16.4(124)$ & & \\
\hline High exposure & $55.6(568)$ & & & $16.6(169)$ & $39.0(398)$ & & \\
\hline FP Media exposure & & 244.30 & $\mathrm{p}<0.000 \mathrm{I}$ & & & 245.00 & $\mathrm{p}<0.0001$ \\
\hline No & $20.6(217)$ & & & $6.8(72)$ & $13.7(145)$ & & \\
\hline Yes & $52.6(627)$ & & & I7.2(205) & $35.4(423)$ & & \\
\hline
\end{tabular}

PDBM: Partner doesn't bring in money; Respt: Respondent; H/P: Husband/partner; SM: spend money; HC: Health Care; FP: Family planning

The data further depict that the binary logistic regression at $7^{\text {th }}$ iteration identified variables such as age, region, residence, ethnicity, education, work status and family planning media exposure as predictors of current use of any contraceptive method. In addition to these variables,; religion and decision-making on how to spend family income were identified using multinomial logistic regression at $9^{\text {th }}$ iteration as predictors of current use of modern contraceptive 
methods (Table 3 in the Appendix D). The data is evidence that women residing in the North East and North West were 0.216(C.I $=0.10 \mathrm{I}$ $0.462 ; p<0.00 I)$ and 0.300 (C.I=0.I45-0.622; $\mathrm{p}<0.0 \mathrm{I}$ ) less likely respectively to be currently using any contraceptive method than their counterparts in the North Central.

Women who are rural dwellers were less likely $(O R=0.6 \mathrm{I} 2 ; \mathrm{C} . \mathrm{I}=0.473-0.794 ; \mathrm{p}<0.000 \mathrm{I})$ to be currently using any contraceptive method than their counterparts living in urban areas. The odds of using any and modern contraceptive methods increases with increasing levels of education and are also higher among women who are currently working. The likelihood of using any and modern contraceptives was higher among the lgbo and Yoruba than the
Hausa ethnic group. For instance, the probability of using a modern contraceptive method was five times higher among the Igbo and Yoruba than the Hausa. Women who reside in the South East were less likely $(O R=0.31 \mathrm{I}$; C.I $=0.152$ 0.636; $p<0.01$ ) to use modern contraceptives than those in North Central. The likelihood of using modern contraceptive methods was higher $(O R=I .686 ; C . I=I .22 I-2.329 ; p<0.0 I)$ among women who themselves and their husband/partner jointly decide on how to spend money than women who make such decisions alone. Also exposure to family planning programmes in the media increases the odds of using modern contraceptives $(O R=1.994$; C.I $=$ I.4 I8-2.804; $p<0.00 I)$.

Table 3 Binary and multinomial logistic regression of currently using any and modern contraceptive method respectively

\begin{tabular}{|c|c|c|c|c|c|c|c|c|}
\hline \multirow{3}{*}{$\begin{array}{l}\text { Background } \\
\text { variables }\end{array}$} & \multicolumn{4}{|c|}{ Any contraceptive } & \multicolumn{4}{|c|}{ Modern contraceptive } \\
\hline & & \multirow[t]{2}{*}{$\operatorname{Exp}(\beta)$} & \multicolumn{2}{|c|}{$95 \%$ C.I for $\beta$} & & \multirow[t]{2}{*}{$\operatorname{Exp}(\beta)$} & \multicolumn{2}{|c|}{$95 \%$ C.I for $\beta$} \\
\hline & & & Lower & Upper & & & Lower & Upper \\
\hline \multicolumn{9}{|l|}{ Age } \\
\hline $15-24$ & 1.515 & $4.550 * *$ & 3.052 & 6.784 & 1.916 & $6.795^{*} *$ & 3.744 & 12.33 \\
\hline $25-34$ & 0.695 & $2.004^{*}$ & 1.367 & 2.938 & 0.961 & $2.614^{*}$ & 1.723 & 3.967 \\
\hline $35-49$ & R.C & 1.000 & R.C & R.C & R.C & 1.000 & R.C & R.C \\
\hline \multicolumn{9}{|l|}{ NSC } \\
\hline $\mathrm{I}-2$ & -1.038 & $0.354 * *$ & 0.179 & 0.700 & -1.292 & $0.275^{* *}$ & 0.117 & 0.643 \\
\hline $3-4$ & -0.252 & 0.777 & 0.590 & 1.025 & -0.370 & $0.691 * * *$ & 0.504 & 0.948 \\
\hline $5+$ & R.C & 1.000 & R.C & R.C & R.C & 1.000 & R.C & R.C \\
\hline \multicolumn{9}{|l|}{ Region } \\
\hline North Central & R.C & 1.000 & R.C & R.C & R.C & 1.000 & R.C & R.C \\
\hline North East & $-|.53|$ & $0.216^{*}$ & 0.101 & 0.462 & -0.959 & $0.383^{* * *}$ & 0.170 & 0.862 \\
\hline North West & -1.203 & $0.300 * *$ & 0.145 & 0.622 & -0.636 & 0.529 & 0.235 & 1.192 \\
\hline South East & -0.469 & 0.626 & 0.338 & 1.159 & -1.169 & 0.311 *** & 0.152 & 0.636 \\
\hline South South & 0.141 & 1.152 & 0.736 & 1.803 & -0.261 & 0.770 & 0.460 & 1.288 \\
\hline South West & 0.226 & 1.254 & 0.800 & 1.967 & 0.230 & 1.259 & 0.765 & 2.071 \\
\hline \multicolumn{9}{|l|}{ Residence } \\
\hline Urban & R.C & 1.000 & R.C & R.C & R.C & 1.000 & R.C & R.C \\
\hline Rural & -0.490 & $0.612 *$ & 0.473 & 0.794 & -0.470 & $0.625 * *$ & 0.465 & 0.839 \\
\hline \multicolumn{9}{|l|}{ Education } \\
\hline No education & R.C & 1.000 & R.C & R.C & R.C & 1.000 & R.C & R.C \\
\hline Primary & 0.791 & $2.206 *$ & 1.486 & 3.275 & 1.035 & $2.814 *$ & 1.742 & 4.545 \\
\hline Secondary & 1.040 & 2.829* & 1.911 & 4.187 & 1.130 & $3.097^{*}$ & 1.915 & 5.009 \\
\hline Higher & $1.27 \mid$ & $3.565^{*}$ & $2.24 I$ & 5.672 & 1.394 & 4.030* & 2.313 & 7.019 \\
\hline \multicolumn{9}{|l|}{ FPME } \\
\hline No & R.C & 1.000 & R.C & R.C & R.C & 1.000 & R.C & R.C \\
\hline Yes & 0.597 & $1.816^{*}$ & 1.360 & 2.425 & 0.690 & I.994* & 1.418 & 2.804 \\
\hline \multicolumn{9}{|l|}{ Ethnicity } \\
\hline Hausa & R.C & 1.000 & R.C & R.C & R.C & 1.000 & R.C & R.C \\
\hline
\end{tabular}




\begin{tabular}{|c|c|c|c|c|c|c|c|c|}
\hline Igbo & 1.340 & $3.821 * *$ & 1.519 & 9.610 & 1.678 & $5.355 * *$ & 1.553 & 18.462 \\
\hline Yoruba & 1.291 & $3.636 * *$ & 1.490 & 8.873 & 1.619 & $5.046 * *$ & 1.541 & 16.530 \\
\hline Others & 0.992 & $2.697 * * * *$ & 1.179 & 6.170 & 1.273 & $3.573 * * * *$ & 1.158 & 11.026 \\
\hline \multicolumn{9}{|l|}{ Religion } \\
\hline Christianity & & & & & R.C & 1.000 & R.C & R.C \\
\hline Islam & & & & & -0.380 & 0.684 & 0.467 & 1.001 \\
\hline Traditional & & & & & -0.514 & 0.598 & 0.116 & 3.071 \\
\hline Others & & & & & 0.611 & $1.842 * * *$ & 1.296 & 7.621 \\
\hline \multicolumn{9}{|l|}{ DHSM } \\
\hline Respondent & & & & & R.C & 1.000 & R.C & R.C \\
\hline Respt. \& H/P & & & & & 0.522 & $1.686 * *$ & 1.221 & 2.329 \\
\hline $\mathrm{H} / \mathrm{P}$ alone & & & & & 0.395 & 1.484 & 0.918 & 2.398 \\
\hline
\end{tabular}

NS: Not significant; RC: Reference Category; *Significant at 0.1\%; **Significant at 1\%; Significant at 5.0\%; FPME: Family planning media exposure; DHSM: Decision on how to spend money

\section{Discussion}

Our study reveals that the prevalence of current use of any contraceptive method among women with no intention to bear more children was quite below average (37.6\%). This is evidence that contraceptive use during sexual intercourse particularly for fertility prevention in Nigeria is still a problem; the consequences reflect in persistent high fertility and accelerated population growth which the country is currently experiencing. High fertility has been considered one of the key factors responsible for high infant mortality (77 per I,000 live birth) and maternal mortality ratio $(545$ per 100,000$)$ in Nigeria (PRB, 2012; NDHS, 2008). These health indices are the core themes of MDGs and PoA recommended at the last international conference on population and development (UN, 2000; UNFPA, 1994). Therefore, achieving these goals will remain a mirage if a framework to improve contraceptive use in Nigeria is ignored.

Mean children ever born (CEB) was higher among women who were not currently using contraceptive methods as compared with their counterparts who were using any of the methods. This is an indication that the likelihood of bearing more children among women with no fertility intention who already had an average of 6.85 children per woman is high in Nigeria. As shown in previous studies, the implication of this envisaged act on the health of the women, children and family can pose threats to population growth and economic development, particularly in a poverty stricken country like Nigeria where infrastructural development remains a problem (Gbola, 2012). In Nigeria, 61.9\% of the popula- tion live below the poverty line and the developmental indicators such as GDP, GNP rank among the poorest globally (NBS, 20I2).

In all age categories, the proportion of women in age group 25-34 constituted the highest among current users of any contraceptive method. This is expected in Nigeria, as women in the age group 25-34 may likely be recently engaged in the labour force that disallows frequent maternity leave. Coital frequency is likely to be higher among this age group and would make them more susceptible to pregnancy than other age groups (Guillermina, 1985). It is fascinating to know that all women aged I5-24 years who are currently using contraceptives used modern methods. This finding reveals the level of sensitization of the youth on the need to use modern contraceptives as fertility reduction preference in Nigeria. If this culture continues and the prevalence of contraceptive use among the youths improves in Nigeria, fertility reduction is likely to be imminent, thus translating into future reduction in population growth.

Our finding that current contraceptive use was significantly higher among Christians than Muslims is consistent with the literature (Helen, 2012; NDHS, 2008; Boniface et al., 2006; NDHS, 2003) and shows that religion remains a fundamental factor in contraceptive use in Nigeria. As previously mentioned, there are numerous consequences of not using contraceptives. Ignoring them can adversely affect a person's life when religious beliefs equate ignorance with virtue and when anxiety and indignity from religious persecution overshadow common sense, people cannot decide on acceptance 
and utilization of contraceptive as they wish. This is contrary to the endorsement at the 1994 International Conference on Population and Development presented in Cairo, Egypt, that the decision of when or even whether to have children is a basic human right (UNFPA, 1994). The religious differences in contraceptive use could be a factor responsible for wide disparity in current contraceptive use among the northern and southern regions in Nigeria as evidenced in this study. Higher proportions of women who currently use contraception was found in all the regions in the southern part of Nigeria than any of the regions in the North. This is consistent with previous findings conducted among all women of childbearing age in Nigeria (NDHS, 1990; NDHS, 1999; NDHS, 2003; NDHS, 2008). As regards the three major ethnic groups in Nigeria, we found a clear differential in contraceptive use between Igbo, Yoruba and Hausa, with the Hausa experiencing the lowest Contraceptive Prevalence Rate (CPR). With this wide gap in the CPR among the ethnic groups in Nigeria, one may be tempted to say that ethnicity was accountable for the regional differences in CPR, as the Northerners are predominantly Hausas.

Among the women with no fertility intention considered in this study, the fraction of women who used any contraceptive method increases with increasing levels of education. The differential in current contraceptive use was particularly striking between women with no formal and higher levels of education and this pattern is similar to the use of modern contraceptives. This finding is expected as the literature is consistent with the view that education has an influence on knowledge, acceptability and utilization of health programs (Saleem and Bobak, 2005; Gordon, 20I I). Education enables the individual to gain access to knowledge of contraceptives, empowers women and thereby improves the uptake and utilization of contraceptives (Radulovi et al., 2006).

Current use of contraceptives, particularly modern methods, was more prominent among women who were working than their counterparts who are not working. Women's empowerment is one of the cornerstones of population and development programmes (UNFPA, 20I2). Nigeria has one of the highest fertility rates of countries in Africa, with women at the receiving end. Women are the ones who bear the risks associated with pregnancy and child delivery. They also breastfeed and provide direct care for babies throughout the childhood periods. In African context, the roles of women are restricted to household chores, but modernization, harsh economic conditions and gender equality campaigns have eroded this philosophy. Nowadays, women work to support the family and their own health needs. Contraceptive access is not completely free in Nigeria. At health facilities levies are charged, distance from the family planning clinic might be far, which then requires transportation fare. All these constitute impediments to the use of contraception in a country like Nigeria, where the population are predominantly poor (Guardian Newspaper, 2012).

Financial self-reliance has emancipated some women from their male partners who might threaten to suspend their financial support if their spouses fail to comply with their sexual needs and health decisions that are particularly beneficial to women (KFF, 2005). It is the refusal of men to use contraceptives that exposes their wives and sexual partners to frequent pregnancy. In most cases, the decision of men usually overrides that of their female sexual partners in terms of contraceptive use, particularly those who are in marital union (Edwards, 1994).

A higher prevalence of contraceptive use was found among women who decide with their partners how to spend family income than those who make such decisions alone. The literature has not addressed this issue; therefore, this finding is not comparable with any previous findings.

Women who were exposed to family planning programmes in news media (radio, television and newspaper) in the 2 months preceding the survey currently use any and modern contraceptive methods than those who did not have any such exposure. In the past, the influence of watching or reading relevant information on a health programme has been identified as an impetus to the uptake and utilization of such programmes (Goni and Rahman, 2012; NFHS bulletin, 1997). Family planning programmes in the media sensitize people on the importance and health implications of using family planning. Knowledge of this information can countermand personal intentions and attitudes previously conceived on the programme. 


\section{Limitations of the study}

The study was based on data obtained through cross-sectional examination of the respondents and as such the data are susceptible to response bias. Self-reported data may reflect a perceived desirability of responses rather than actual knowledge or practices. The spouse communication variable was not included in the study simply because of their absence in the list of variables included in the original questionnaire used for the data collection. This is an important variable in contraceptive research. The shortcomings associated with the use of secondary data cannot be completely eliminated from the findings of this study.

\section{Conclusion}

The identified predictors of current use of contraceptives among women who had no intention of bearing more children were: age, region, residence, education, ethnicity and family planning media exposure. In addition to these variables, religion and decision on how to spend family income were also identified as predictors of the current use of modern contraceptive methods. The use of contraceptives was not adequately practised in Nigeria. Specifically, the Nigerian government should integrate factors identified in this study as the predictors of contraceptive use into fertility impact assessments and other planning and decision-making processes aimed at achieving sustainable development. This will facilitate a reduction in the fertility rate and population growth rate in Nigeria.

\section{Acknowledgement}

The authors are grateful to Macro-International U.S.A. and National Population Commission for allowing us to use their data (NDHS, 2008) for this study.

\section{References}

Adebowale SA, Fagbamigbe FA and Bamgboye EA. (20II). Contraceptive Use: Implication for Completed Fertility, Parity Progression and Maternal Nutritional Status in Nigeria. African Journal of Reproductive Health December 201 I; 15(4): 60

Adebowale SA, Fagbamigbe FA, and Bamgboye EA. (2010). Rural-Urban Differential in Maternal
Mortality Estimate in Nigeria, Sub-Saharan Africa. Journal of Medical and Applied Biosciences. Volume 2, September 2010 Pg: 74-9I

Arab A.A, Bener A and Abdulmalik M. (20II). Prevalence, awareness and determinants of contraceptive use in Quatari Women. Eastern Mediterranean Health Journal Vol I7 Nol.20II

Bankole A, Oye-Adeniran BA, Singh S, Adewole IF, Wulf D, Sedgh G. Hussain R. (2006). Unwanted pregnancy and induced abortion in Nigeria: Causes and consequences. New York. Gutmacher Institute

Boniface A. Oye-Adeniran, Isaac F. Adewole, Augustine V. Umoh, Adesina Oladokun, Abidoye Ghadegesin, Ekanem E. Ekanem, Bidemi Yusuf, Kofo A. Odeyemi, Ngozi Iwere and Pat Mahmoud (2006). Community-based Study of Contraceptive Behaviour in Nigeria. African Journal of Reproductive Health Vol. 10, No. 2 (Aug., 2006), pp. 90-104

CBN (2002). A report of Central Bank of Nigeria

Edwards SR. (1994). The Role of Men in Contraceptive Decision-Making: Current Knowledge and Future Implications .Family Planning Perspectives. Vol. 26, No. 2 (Mar. - Apr., 1994), pp. 77-82

FHI. Men's Involvement in Emergency.

Contraceptive Use in Ghana FHI Headquarters. Perspectives on Gender and Health 2224 E NC Hwy 54 Durham, NC 277I 3 USA

Gbola Subair (20I2). Nigeria's poverty level rises, Sokoto, Niger top list of poorest states. Tribune newspaper Monday, I 3 February 2012

Goldberg HI, McNeil M and Spitz A. (1989). Contraceptive Use and Fertility Decline in Chogoria, Kenya. Studies in Family Planning. Vol. 20, No. I (Jan. - Feb., I989), pp. 17-25

Goni A, Rahman M. (20/2). The impact of education and media on contraceptive use in Bangladesh: A multivariate analysis. Int J Nurs Pract. 2012 Dec; 18(6):565-73. doi: 10.1 I I I/ijn. 12013.

Gordon C. (20II). Women's Education and Modern Contraceptive Use in Ethiopia. International Journal of Education ISSN 1948-5476; 20I I, Vol. 3, No. I: E9

Guardian Newspaper (2012). Rising poverty level in Nigeria worries UNDP Thursday, 30 August 2012 00:00 Editor Business Services - Business News

Guillermina Jasso (1985). Marital Coital Frequency and the Passage of Time: Estimating the Separate Effects of Spouses' Ages and Marital Duration, Birth and Marriage Cohorts, and Period Influences. American Sociological Review Vol. 50, No. 2 (Apr., 1985), pp. 224-24I

USAID (2009). Health Policy Initiative Task Order I, 
2009. Family Planning and the MDGs: Saving Lives, Saving Resources. United States Agency for International Development.

Helen N. (2012). Relationship between Religion and Use of Modern Contraceptives among the Atyap in Kaduna State, Nigeria. Avong Research on Humanities and Social Sciences. ISSN 2222-1719 (Paper) ISSN 2222-2863 (Online) Vol 2, No.8, 2012

KFF (2005). Women and Health Care: A national profile. Key findings from the kaiser women's health survey. Kaiser Family Foundation.

Mensch Barbara Sena (1985). The Effect of Child Mortality on Contraceptive Use and Fertility in Colombia, Costa Rica and Korea Population Studies Vol. 39, No. 2 (Jul., 1985), pp. 309-327. Published by: Taylor \& Francis

Moronkola OA, Ojediran MM, Amosu A. (2006). Reproductive Health knowledge, belief and determinants of contraceptive use among women attending family planning clinics in Ibadan, Nigeria. Africa Health Sciences, 2006, 6:155-159

NBS (2012). National Bureau of Statistics report Abuja, 2012

National Population Commission Nigeria and ICF Macro (2009). Nigeria Demographic and Health Survey 2008. Abuja, Nigeria: National Population Commission and ICF Macro.

NDHS (2003). Nigeria Demographic and Health Survey 2003. Calverton, Maryland: National Population Commission and Macro.

NDHS (2008). Nigeria Demographic and Health Survey 2008. Abuja, Nigeria: National Population Commission and ICF Macro.

NFHS bulletin (1997). Media exposure increases contraceptive use. National Family Health Survey 1993. International Institute for Population Sciences. ISSN 1083-8678

NDHS. (1991). Nigeria Demographic and Health Survey 2008. National Population Commission and ICF Micro, Calverton, MD 0705, USA

NDHS. (1999). Nigeria Demographic and Health Survey. National Population Commission and ICF Micro, Calverton, MD 0705, USA

NPC (2004). Revised Population Policy in Nigeria. National Population Commission, Federal Republic of Nigeria

Odimegwu C.O, Ojo M, Siyangande A. (1997). Regional correlates of choice of contraceptive methods in Nigeria. Korean Journal of Population and Development 1997; vol 26, I

Omo-Aghoja L.O, Omo-Aghoja V.W, Aghoja C.O, Okonofua F.E, Aghedo.O, Umueri .C (2009).
Factors associated with the Knowledge, Practice and Perceptions of Contraception in Rural Southern Nigeria. Ghana Medical Journal 2009 Vol 43 No 3.

Oyedokun A.O. (2007). Determinants of contraceptive Usage: Lessons from Women in Osun State, Nigeria J Humanities Social Sciences 2007; I- 14

PRB (20/2). World Population Datasheet by Population Reference Bureau

Radheshyam Bairagi (200I). Effects of Sex Preference on Contraceptive Use, Abortion and Fertility in Matlab, Bangladesh. International Family Planning Perspectives. Volume 27, Number 3, September 200 I

Radulovi O, Šagri C, Višnji A, Tasi A, Markovi R. (2006). The influence of education level on family planning. Facta Universitatis Series: Medicine and Biology Vol.13, No I, 2006, pp. 58 - 64 UC 37.046:6।3.88:314.33.6

Saha UR and Bairagi R. (2007). Inconsistencies in the Relationship between Contraceptive Use and Fertility in Bangladesh. International Family Planning Perspectives Volume 33, Number I, March 2007

Saleem S and Bobak M. (2005). Women's autonomy, education and contraception use in Pakistan: a national study. Reproductive Health 2005, 2:8 doi: 10.1 I86/1742-4755-2-8.

Satyavada A, Adamchak DJ. (2000). Determinants of current use of contraception and children ever born in Nepal. Soc Biol. 2000 SpringSummer;47(I-2):5I-60

Shah NM, Kazi SF. (1977). Attitudes, contraceptive practice and children ever born among currently married women exposed to different types of communication media, Pakistan. Dev Rev. 1977 Winter; I6(4):405-23.

Umoh A.V, Abah G.M and Ekanem U.S. (20I2). A study of fertility intentions of women in Uyo, Nigeria. Journal of public Health and Epidemiology Vol 4(I), pp I4-18, January 2012.

UN (2000). Millennium Development Goals

UNFPA. (1994). Programme of Action of the report of International Conference on Population and Development Held in Cairo, 1994

UNFPA. (20I2). Ten Good Practices in Essential Supplies for Family Planning and Maternal Health. UNFPA

WHO (2005). Maternal mortality ratio in 2005: Estimates by UNICEF, WHO, UNFPA, World Bank. Geneva: WHO; 2004. 